\title{
Universiteit
}

Leiden

The Netherlands

\section{Intracellular bacterial growth is controlled by a kinase network around PKB/AKT1}

Kuijl, C.; Savage, N.D.L.; Marsman, M.; Tuin, A.W.; Janssen, L.; Egan, D.A.; ... ; Neefjes, J.J.

\section{Citation}

Kuijl, C., Savage, N. D. L., Marsman, M., Tuin, A. W., Janssen, L., Egan, D. A., ... Neefjes, J. J. (2007). Intracellular bacterial growth is controlled by a kinase network around PKB/AKT1. Nature, 450, 725-730. doi:10.1038/nature06345

Version: $\quad$ Publisher's Version

License: $\quad$ Licensed under Article 25fa Copyright Act/Law (Amendment Taverne)

Downloaded from: https://hdl.handle.net/1887/3209535

Note: To cite this publication please use the final published version (if applicable). 


\title{
Intracellular bacterial growth is controlled by a kinase network around PKB/AKT1
}

\author{
Coenraad Kuijl ${ }^{1}$, Nigel D. L. Savage ${ }^{3}$, Marije Marsman ${ }^{1}$, Adriaan W. Tuin ${ }^{4}$, Lennert Janssen ${ }^{1}$, David A. Egan ${ }^{2}$, \\ Mirjam Ketema ${ }^{1}$, Rian van den Nieuwendijk ${ }^{4}$, Susan J. F. van den Eeden ${ }^{3}$, Annemieke Geluk ${ }^{3}$, Alex Poot ${ }^{4}$, \\ Gijs van der Marel ${ }^{4}$, Roderick L. Beijersbergen ${ }^{2}$, Hermen Overkleeft ${ }^{4}$, Tom H. M. Ottenhoff ${ }^{3}$ \& Jacques Neefjes ${ }^{1}$
}

With the emergence of multidrug resistant (MDR) bacteria, it is imperative to develop new intervention strategies. Current antibiotics typically target pathogen rather than host-specific biochemical pathways ${ }^{1}$. Here we have developed kinase inhibitors that prevent intracellular growth of unrelated pathogens such as Salmonella typhimurium and Mycobacterium tuberculosis. An RNA interference screen of the human kinome using automated microscopy revealed several host kinases capable of inhibiting intracellular growth of $S$. typhimurium. The kinases identified clustered in one network around AKT1 (also known as PKB). Inhibitors of AKT1 prevent intracellular growth of various bacteria including MDR-M. tuberculosis. AKT1 is activated by the S. typhimurium effector SopB, which promotes intracellular survival by controlling actin dynamics through PAK4, and phagosome-lysosome fusion through the AS160 (also known as TBC1D4)-RAB14 pathway. AKT1 inhibitors counteract the bacterial manipulation of host signalling processes, thus controlling intracellular growth of bacteria. By using a reciprocal chemical genetics approach, we identified kinase inhibitors with antibiotic properties and their host targets, and we determined host signalling networks that are activated by intracellular bacteria for survival.

A major bottleneck in the development of new antibiotics is our lack of knowledge of the intricate relationship between host and bacterial proteins, which usually results in intracellular survival of the pathogen. Intracellular bacteria persist in phagosomes where they avoid degradation in lysosomes ${ }^{2,3}$. S. typhimurium modulates microtubular kinesin motors on phagosomes ${ }^{4}$ and manipulates dyneinmotor-driven transport of phagosomes to lysosomes to rescue Salmonella growth ${ }^{5}$. Salmonella activates host kinases like protein kinase A (PKA $)^{6}$, which might inhibit dynein motors ${ }^{7}$ to promote Salmonella replication. We therefore set out to identify host kinases as potential intervention targets in infectious diseases.

We tested selected kinase inhibitors for effects on intracellular Salmonella typhimurium growth in the human breast cancer cell line MCF7 (Fig. 1a). MCF7 cells were infected with Lux-expressing S. typhimurium SL12023 and cultured with inhibitors for $18 \mathrm{~h}$. The effect on intracellular growth was monitored by luminescence (Fig. 1a), colony-forming units (c.f.u.) and fluorescence-activated cell sorting (FACS) assays (not shown). Only H-89 prevented intracellular growth of $S$. typhimurium without affecting proliferation of MCF7 cells. This was confirmed in various human and mouse cell lines (not shown), including primary human macrophages (Fig. 2b). Because two other inhibitors of PKA failed to affect S. typhimurium growth (Supplementary Fig. 1), H-89 probably inhibited kinases other than PKA. When MCF7 cells were infected with green fluorescent protein (GFP)-expressing S. typhimurium SL1344 for $18 \mathrm{~h}$, large intracellular $S$. typhimurium structures in CD63-positive late endosomes were observed in control but not $\mathrm{H}$-89-treated cells (Fig. 1b). H-89 promoted fusion of GFP-S. typhimurium-containing phagosomes with lysosomes (not shown). H-89 could have affected an S. typhimurium kinase, however bacterial growth was unaltered by $\mathrm{H}-89$ in normal broth or under conditions mimicking the phagosomal environment (Fig. 1c).

To define host kinases involved in intracellular growth of S. typhimurium and other intracellular pathogens, H-89 analogues were synthesized for chemical profiling (Fig. 2a; synthesis, Supplementary Fig. 2). H-89 competes with ATP for access to kinases ${ }^{8}$. Enzyme specificity can be obtained by varying the linker in length and form and by modifying the bulky moiety. The effects of H-89 and nine variants were tested on intracellular $S$. typhimurium growth in primary human macrophages (Fig. 2b). S. typhimurium proliferation was inhibited by H-89, ETB067 and ETB275.

The activity of H-89-related variants was then examined on two mycobacterial strains, M. smegmatis (Supplementary Fig. 3) and $M$. tuberculosis, following human macrophage infection (Fig. 2c). Similar chemical profiles to S. typhimurium infection were obtained, suggesting similar host kinases control intracellular growth of different pathogens.

To identify these, a Dharmacon short interfering (si)RNA library containing 779 siRNA smartpools targeting the complete human kinome (658 candidates) and 121 kinase-associated or -regulatory proteins was tested in a high-throughput screen for inhibition of intracellular S. typhimurium growth using automated microscopy. Because H-89 and most analogues did not affect macrophage and MCF7 viability (Supplementary Fig. 4), silencing relevant kinase(s) by siRNA should neither affect cell viability. MCF7 cells were transfected with SMARTpool siRNA such that one defined kinase was targeted per well. Two days post transfection, cells were infected with GFP-expressing S.typhimurium SL1344, intracellular growth monitored $18 \mathrm{~h}$ post infection by automated microscopy (Fig. 3a) and 26,000 images analysed (Supplementary Figs 5 and 6). By quantifying GFP within cells (Supplementary Fig. 5), intracellular growth of S. typhimurium was determined, and plotted as a heat map (Supplementary Fig. 8c; for details on individual kinase targets and statistics see Methods). Data were visually verified and confirmed with a short hairpin (sh)RNA library specific to human kinases ${ }^{9}$ (Supplementary Fig. 7). Downregulation of 11 kinases and 3 kinase-associated proteins reduced intracellular S. typhimurium growth (Fig. 3b). Ten of these kinases were validated with multiple siRNAs for the same kinase 
(Fig. 3b, and Supplementary Fig. 8a, b). These targets were not identified in RNAi screens for host factors after intracellular infection of Drosophila melanogaster macrophage-like cells with M. tuberculosis or M. fortuitum ${ }^{10,11}$. AKT1 is involved in SimianVirus40 infection, but other kinases such as PAK4 were not identified in these RNAi
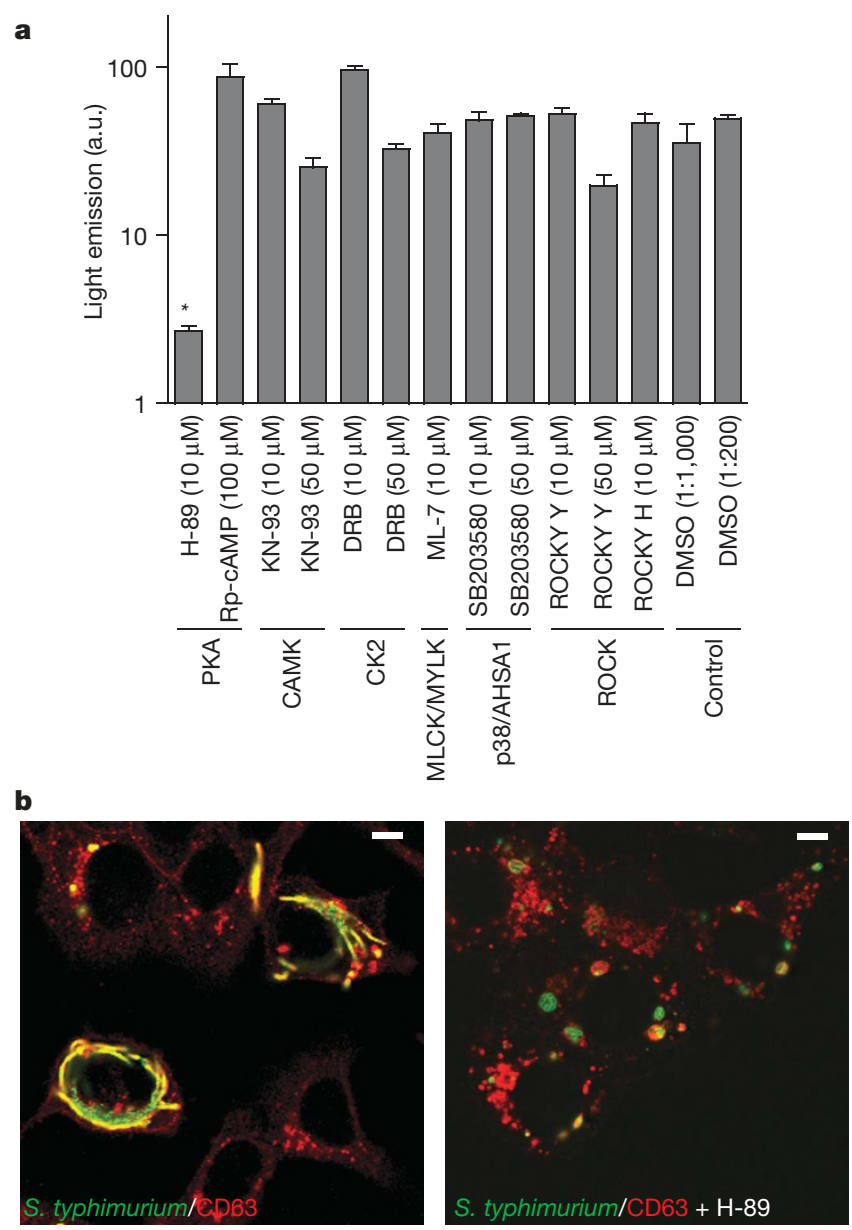

c

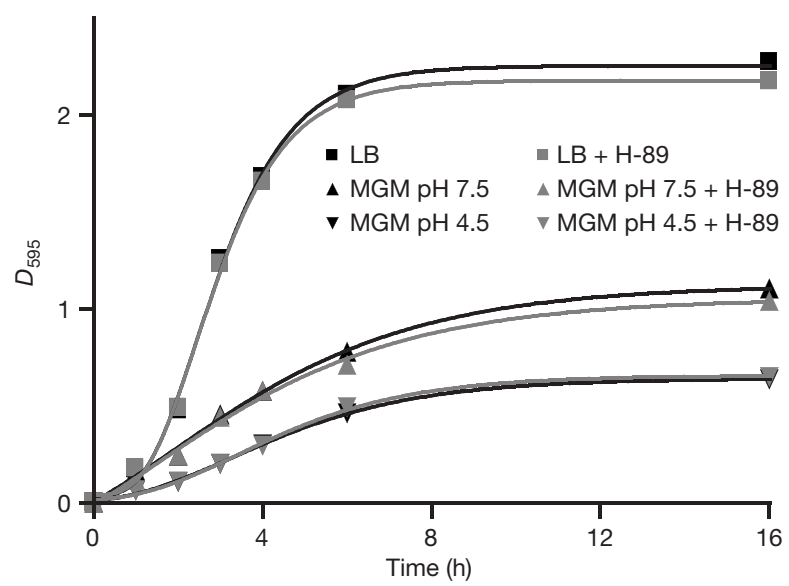

Figure 1 | The protein-kinase-A inhibitor H-89 inhibits host kinases that control intracellular Salmonella typhimurium growth. a, MCF7 cells infected with Lux-S. typhimurium were cultured for $18 \mathrm{~h}$ with the various chemicals. The intracellular S. typhimurium was quantified by luminometry. Inhibitors and kinase targets are indicated. Experiments were in triplicate ( \pm s.d.) $\left({ }^{*} P=0.017\right)$. CK2 is also known as CSNK2A1. b, MCF7 cells were infected with GFP-S.typhimurium SL1344 and cultured with H-89 for $18 \mathrm{~h}$ before staining for the late endosomal marker CD63 $(n>100)$. Scale bar, $10 \mu \mathrm{m}$. c, $S$. typhimurium growth in LB or a medium mimicking endosomal conditions (MGM) in the presence or absence of $10 \mu \mathrm{M} \mathrm{H}-89$ at $\mathrm{pH} 7.5$ or $\mathrm{pH} 4.5$ was measured at a wavelength of $595 \mathrm{~nm}$. studies $^{12}$. Of the three AKT enzymes, our screen identified only AKT1, which is selectively targeted by H-89 (not shown). No apoptosis was observed after downregulation of AKT1 by siRNA or inactivation by H-89 (Fig. 3a), because this requires inactivation of AKT1 and AKT2 (R.L.B., unpublished observation). Autophagy was not observed (Supplementary Fig. 9).

Pathway analyses of data revealed that kinases controlling intracellular growth of S. typhimurium clustered around a single AKT1 network (Fig. 3c), suggesting this network is critical for intracellular S. typhimurium growth. To determine which kinases were targets of H-89 and its homologues, PKA and four other similar kinases (Supplementary Fig. 10) were tested for inhibition by H-89 and six variants (Fig. 4a). Only PKA and AKT1 activities were inhibited by H-89 and ETB067, in accordance with the chemical profile of intracellular bacterial growth inhibition (Fig. 2). Because PKA was not identified in the siRNA screen and other PKA inhibitors did not affect intracellular S. typhimurium growth (Fig. 1a; and Supplementary Fig. 1), AKT1 might be the target for H-89 and ETB067. An unrelated

a<smiles>[R]c1ccc(CC[NH+](C)CCNS(=O)(=O)c2cccc3cnccc23)cc1</smiles>

ETB007: $n=1, \mathrm{R}=\mathrm{H}$ ETB008: $n=2, \mathrm{R}=\mathrm{H}$ ETB009: $n=3, \mathrm{R}=\mathrm{H}$ ETB010: $n=4, \mathrm{R}=\mathrm{H}$ ETB273: $n=1, \mathrm{R}=\mathrm{Br}$ ETB275: $n=3, \mathrm{R}=\mathrm{Br}$

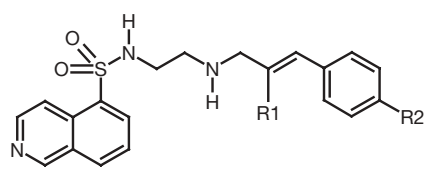

ETB064A: $\mathrm{R} 1=\mathrm{H}, \mathrm{R} 2=\mathrm{H}$ $\mathrm{H}-89: \mathrm{R} 1=\mathrm{H}, \mathrm{R} 2=\mathrm{Br}$ ETB064B: R1 = Me, R2 = H ETB067: R1 = Me, R2 $=\mathrm{Br}$

b

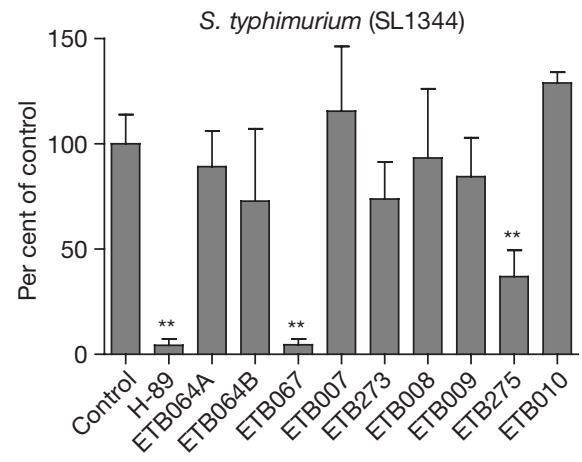

c

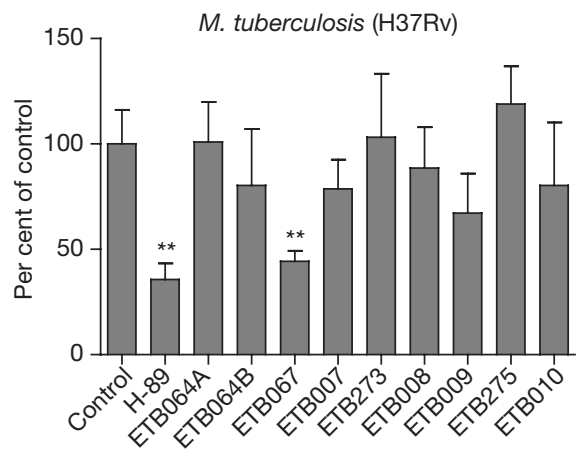

Figure 2 | Chemical profiling for antibiotic activity of kinase inhibitors. a, The building block H-89 was selectively modified. For synthesis see Supplementary Fig. 2. b, Chemical profiling for S. typhimurium infection. Primary human macrophages infected with S. typhimurium SL1344 were cultured in the presence of $10 \mu \mathrm{M}$ of the compounds for $18 \mathrm{~h}$. Intracellular growth was determined in c.f.u. assays. Shown is the mean of quadruplicate c.f.u. counts \pm s.e.m. $\left({ }^{*} P<0.001\right)$ c, Chemical profiling for M. tuberculosis infection. Primary human macrophages infected with M. tuberculosis were cultured as in $\mathbf{b}$ for 6 days with daily renewal of medium, and intracellular growth determined. Shown is the mean of quadruplicate c.f.u. counts \pm s.e.m. $(* * P<0.001)$ 
PKB inhibitor AKTi1/2 (which does not inhibit PKA; Fig. 4a) also inhibited intracellular propagation of S. typhimurium and M. smegmatis in human macrophages and MCF7 cells (Supplementary
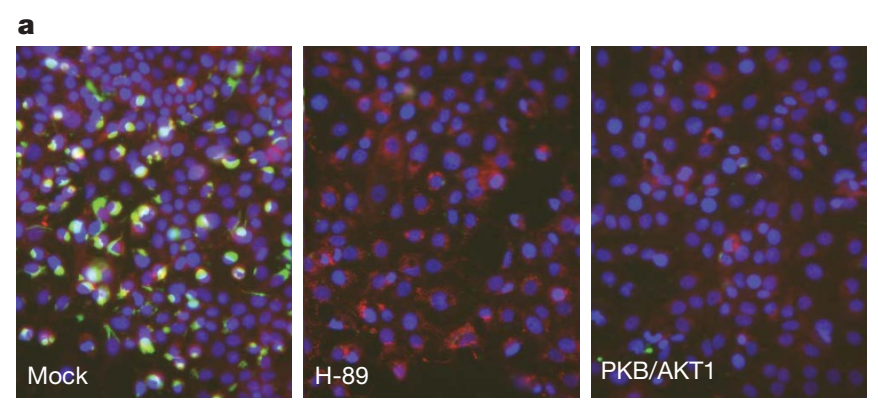

b

\begin{tabular}{llcl}
\hline Gene & Method & Validated & Confirmation \\
\hline ABL1 & siRNA & + & qPCR \\
CAMK2B & siRNA & + & \\
FASTK & SiRNA & + & \\
LYN & SiRNA & - & \\
MAP3K14 & SiRNA & + & \\
PAK4 & shRNAi & + & qPCR \\
PCTK1 & SiRNA & + & \\
PIK3C2G & SiRNA & + & qPCR \\
PIK3CA & SiRNA & + & qPCR \\
PKB/AKT & SiRNA & + & WB \\
PRKD2 & SiRNA & + & qPCR \\
CALM3 & SiRNA & & \\
CINP & SiRNA & & \\
MAPK8IP2 & SiRNA & &
\end{tabular}

c

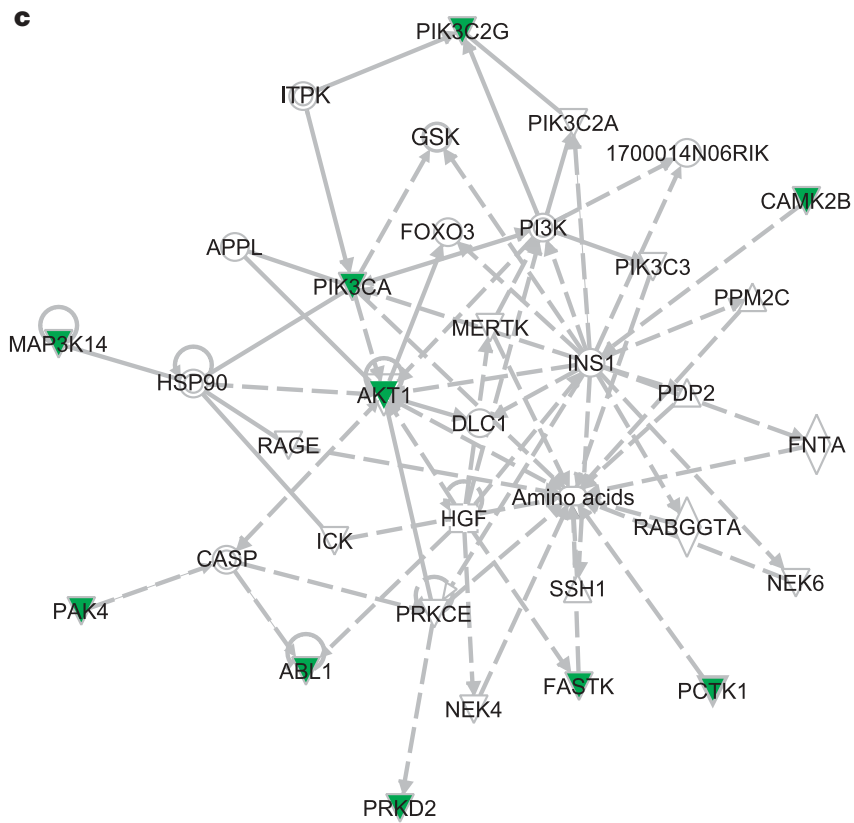

Figure 3 | Identification of host kinases controlling intracellular growth of $S$. typhimurium. a, Automated-microscopy images from mock- and H-89treated, as well as $A K T 1$-siRNA-transfected MCF7 cells (magnification, $\times 40$ ). Blue, nuclei; red, cell boundaries; green, GFP-S. typhimurium. Intracellular growth (amount of GFP-S. typhimurium per infected cell) was calculated from these images (Supplementary Figs 5 and 6). For details on individual siRNA targets and statistics, see Supplementary Fig. 8. b, Identified targets: CALM3, CINP and MAPK8IP2 are kinase-associated hits. Hits were confirmed in an independent shRNAi screen and validated by two or more independent siRNAs indicated (Supplementary Fig. 8). Downregulation of targets was determined by quantitative qPCR or western blotting (WB) (Supplementary Fig. 8). c, Ingenuity Pathway Analysis of the kinase candidates affecting intracellular growth of $S$. typhimurium. In the network, the ten validated kinases are coded green. Open symbols, connecting proteins. PI3K, series of PI3Ks (PIK3C2G, PIK3CA, PIK3CB, PIK3CD and PIK3CG).
Fig. 11). AKTil/2 (which inhibits AKT1 and AKT2) induced apoptosis in long-term cultures, unlike H-89 and analogues (Supplementary Fig. 4), and therefore the effect on slowly replicating pathogen $M$. tuberculosis could not be determined.

Host kinase AKT1 represents a new target for combating MDRpathogens like MDR-M. tuberculosis, which should be sensitive to ETB067 and H-89. Indeed, human macrophages infected with MDRM. tuberculosis (Beijing/W family) and cultured with various H-89 analogues showed similar chemical profiles (Fig. 4b) to S. typhimurium, M. smegmatis and M. tuberculosis (Fig. 2b, c, and Supplementary Fig. 3)

The various compounds may determine sites in $\mathrm{H}-89$ to increase the specificity for AKT1. ATP-binding sites of PKA and AKT1 are highly similar and H-89 fills this in a 'bended' conformation (Supplementary Fig. 12) ${ }^{13}$. The H-89 isoquinoline group mimics the ATP adenine group and the bromo-phenyl group fills a pocket that is identical in PKA and $\mathrm{AKT} 1^{13}$. Changing the halogen probably does not improve selectivity of the compounds, but, at best, affinity. Manipulating the linker length may position the isoquinoline-group and the bulky moiety incorrectly for an optimal fit into the ATPbinding site thus reducing affinity, as observed (Figs 2, 4a). The reduced bond in the linker bends the inhibitor in the active site of PKA and AKT1 (Supplementary Fig. 12) and improves affinity but

a

\begin{tabular}{|c|c|c|c|c|c|c|c|c|c|}
\hline $\mathrm{IC}_{50}(\mu \mathrm{M})$ & $\begin{array}{l}\stackrel{8}{\infty} \\
1 \\
I\end{array}$ & 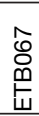 & 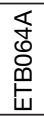 & 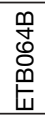 & $\begin{array}{l}\hat{\delta} \\
\Phi \\
\underline{\Phi}\end{array}$ & 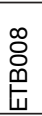 & $\begin{array}{l}\stackrel{8}{8} \\
\stackrel{0}{6} \\
w\end{array}$ & $\begin{array}{l}\text { 음 } \\
\text { m } \\
\underline{w}\end{array}$ & $\underset{\frac{\mathbb{E}}{\mathbb{K}}}{\stackrel{N}{\alpha}}$ \\
\hline KA & 2 & 10 & 70 & 80 & - & - & - & - & - \\
\hline DKB/AK & 2 & 10 & - & 80 & & - & - & - & 3 \\
\hline CAM & 10 & - & - & - & ND & ND & ND & ND & ND \\
\hline PRKD2 & 75 & - & - & - & - & - & - & - & ND \\
\hline PAK4 & - & - & - & - & - & - & - & - & ND \\
\hline PCTK1 & - & - & - & - & - & - & - & - & - \\
\hline
\end{tabular}

b
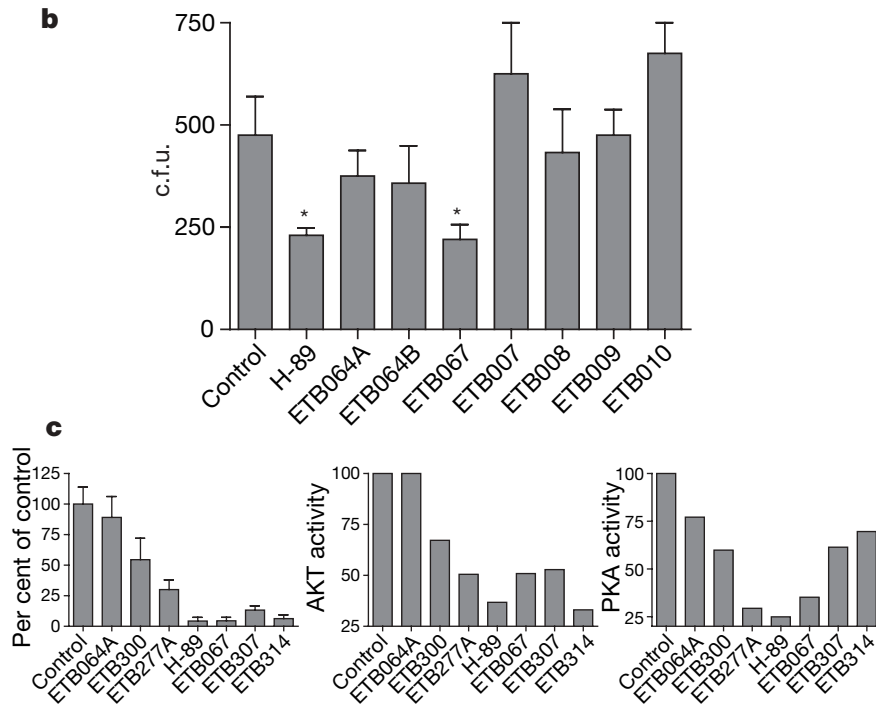

Figure 4 | Identification of host kinase targets for the chemical compounds inhibiting S. typhimurium and (MDR-)M. tuberculosis. a, In vitro kinase reaction with purified PKA, AKT1 and 4 GFP-tagged kinase domains. The half-maximal inhibitory concentration $\left(\mathrm{IC}_{50}\right)$ of kinase activity is determined. -, $\mathrm{IC}_{50}>100 \mu \mathrm{M}$; ND, not determined. $\mathbf{b}$, Human primary macrophages were infected with MDR-M. tuberculosis MDR16319 and cultured for 6 days in the presence of various kinase inhibitors. Shown is the mean of quadruplicate c.f.u. counts \pm s.e.m. $(* P>0.05)$. c, The effects of H-89 variants (Supplementary Fig. 13) on intracellular S. typhimurium growth in human macrophages was tested $18 \mathrm{~h}$ post infection, determined by c.f.u. assays and related to untreated cells, set at $100 \%$ (left panel; shown is the mean of quadruplicate experiments \pm s.e.m.). In addition, inhibition of $10 \mu \mathrm{M}$ of compounds on isolated AKT1 (middle panel) or PKA (right panel) is shown as a mean of triplicate experiments. 
not selectivity (Figs 2 and 4). The methyl group in the linker of ETB067 generated specificity, because CAMK2B is no longer inhibited by ETB067 (Fig. 4a). We increased the size of our chemical library and extended the methyl group in the linker and/or altered the halogen (Supplementary Fig. 13). Human macrophages were infected with S. typhimurium and the compounds tested (Fig. 4c; left panel). Replacing $\mathrm{Br}$ in $\mathrm{H}-89$ for smaller halogens or hydrogen attenuated inhibition of intracellular S. typhimurium growth and decreased inhibition of both AKT1 and PKA (Fig. 4c). Extending the methyl group in the linker region of ETB067 did not affect bactericidal activity but selectively decreased PKA inhibition (Fig. 4c, and Supplementary Fig. 13). All combinations (halogens and extensions in the linker side chain) were tested for their effects on intracellular growth of S. typhimurium (Supplementary Fig. 13). The effect on intracellular $S$. typhimurium replication of the $16 \mathrm{H}-89$ variants was cross-correlated with the rate of AKT1 or PKA inhibition. An obvious correlation was observed only for AKT1 (Supplementary Fig. 13).

Application of compound ETB067 to S. typhimurium-infected mice following the first signs of illness prolonged survival (Supplementary Fig. 14). Notably, ETB067 neither affected viability of mice nor caused any detectable tissue damage at the dose given (Supplementary Fig. 15). Although better AKT inhibitors have entered clinical trials as anti-cancer drugs, application of our compounds illustrates the feasibility of using AKT inhibitors as antibiotics.

We next studied the mechanism of AKT inhibitors as bacteriostatic or bactericidal agents. AKT contains a $\mathrm{PH}$ domain, which binds phosphoinositides. Phosphoinositides are frequently manipulated and AKT often activated by intracellular bacteria ${ }^{14}$. S. typhimurium secretes SopB, an effector protein with phosphoinositide phosphatase activity into the host cytosol, and analogous effectors were identified for Shighella flexneri ${ }^{15}$. The resulting activation of AKT may prevent phagosomal maturation ${ }^{16}$ and promote survival under nutrient-poor phagosomal conditions ${ }^{17}$. Other bacterial effectors activate the small GTPase Rac1, which controls actin dynamics during and following phagocytosis ${ }^{18}$. To show AKT activation by SopB, we infected MCF7 cells with control or SopB-deficient S. typhimurium before staining for activated S473-phosphorylated AKT (Fig. 5a). SopB activates AKT at the plasma membrane but not on phagosomes.

Because PAK4 activity is controlled by phosphatidylinositol-3-OH kinases ${ }^{19}$, PAK4 (also identified in our screen) could be downstream of AKT. PAK4 binds to, but is not activated by CDC42 and phosphorylates the RHO/RAC GEF-H1 (also known as ARHGEF2), which then fails to activate RHOA, instead activating $\mathrm{RACl}^{20}$ and resulting in different and local effects on actin. We first showed that PAK4 was phosphorylated in cells expressing activated AKT1 and then showed that the phosphorylated PAK4 was more active (Supplementary Fig. 16a). AKT1 then lies upstream of PAK4, thus controlling RHOA, RAC1 and actin remodelling.

To test whether activation of the AKT-PAK4 axis aids survival of intracellular pathogens, MCF7 cells expressing control or constitutively active PAK4(S445N) ${ }^{21}$ were infected with S. typhimurium and cultured in the presence or absence of AKT inhibitor AKTi1/2. Intracellular growth of DsRed-S. typhimurium was determined $18 \mathrm{~h}$ post infection by FACS (Fig. 5b). GFP-PAK4(S445N) only partially rescued intracellular expansion of DsRed-S. typhimurium in the presence of AKTi1/2, implying that other pathways downstream of AKT1 should also be involved.

Phagosome-lysosome fusion effects were reported in Dictyostelium discoideum ${ }^{22}$, in which activation of AKT delays fusion of phagosomes to lysosomes to promote pathogen survival. Our inhibitors may counteract this block in phagosomal maturation, thus inducing lysosome fusion. Preventing lysosomal acidification therefore obscured effects of AKT inhibitors (Supplementary Fig. 16b). At least 18 Rab GTPases are implicated in phagosomal maturation ${ }^{23}$. RAB14 is involved in the control of M. tuberculosis phagosomal
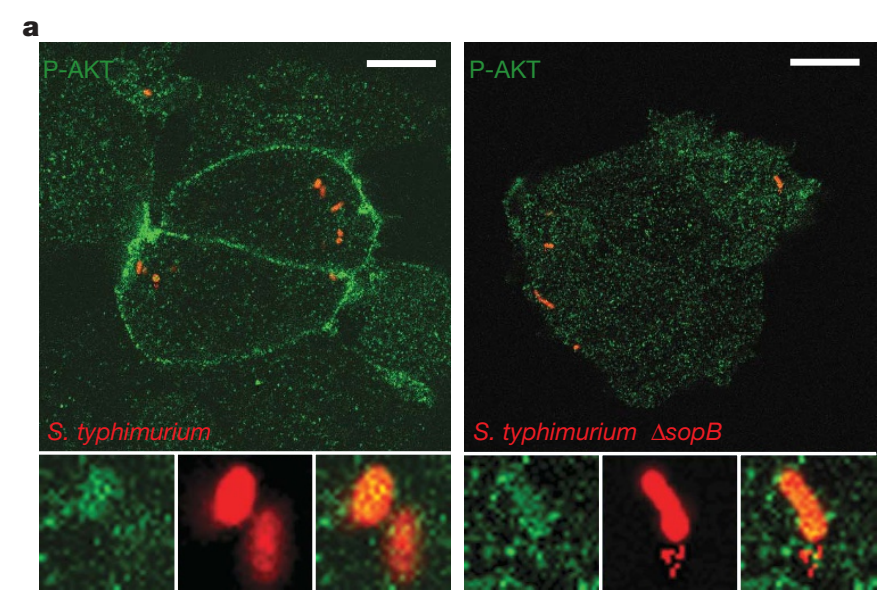

b

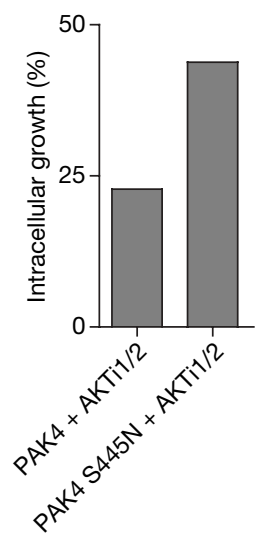

c
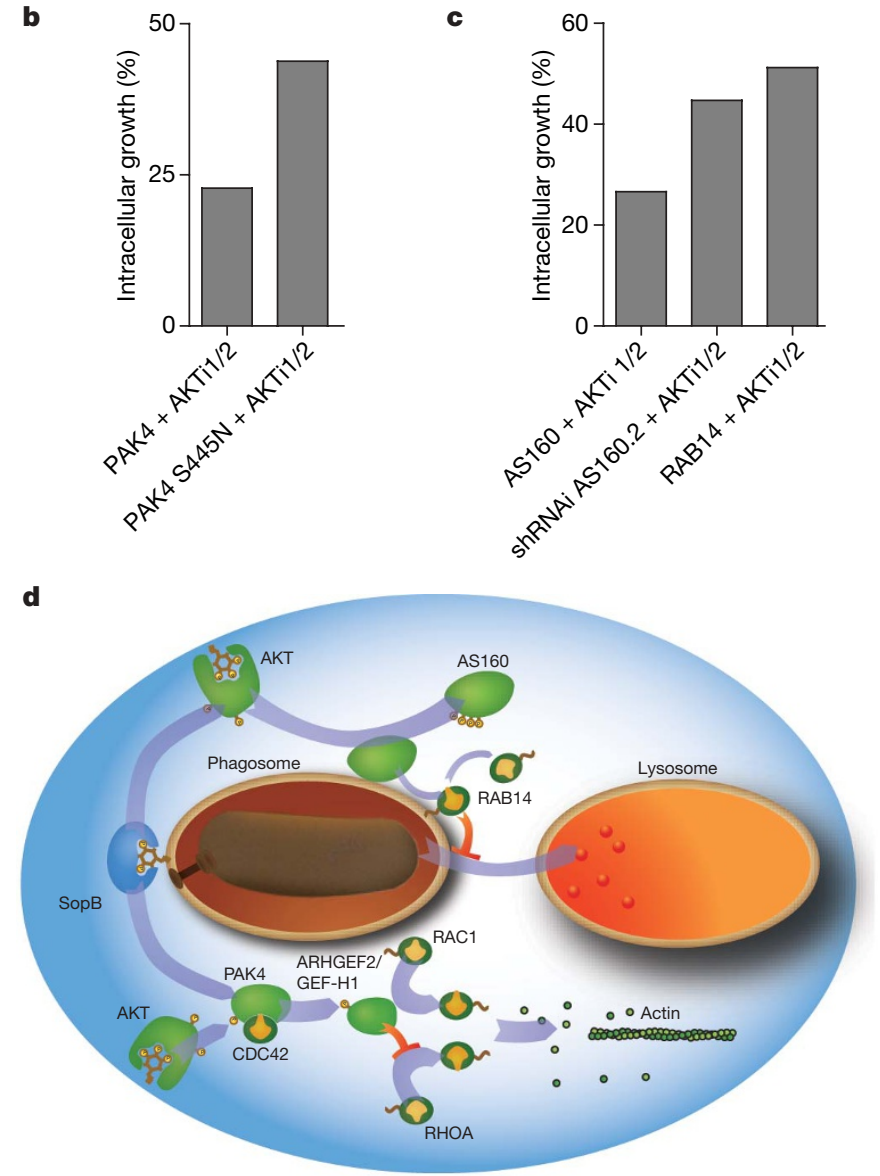

Figure 5 | Mechanisms of AKT1 control of intracellular S. typhimurium infections. a, MCF7 cells infected with control or SopB-deficient DsRedexpressing $S$. typhimurium before staining for activated AKT (P-AKT). Insets, higher magnification $(n>100)$. Scale bar, $10 \mu \mathrm{m}$. b, GFP-labelled PAK4 or constitutively active PAK4(S445N) expressed in MCF7 cells were infected and cultured with DsRed-S.typhimurium for $18 \mathrm{~h}$ with AKTi1/2. DsRed-S. typhimurium were quantified by FACS and related to the infection of GFP-PAK4-transfected cells, set at $100 \%$. Shown is the mean of triplicate experiments. c, MCF7 cells were transfected with Myc-RAB14, AS160 or the shRNAi AS160.2 construct for AS160, and infected with GFP-S. typhimurium in the presence or absence of AKTi1/2. Intracellular $S$. typhimurium was quantified by FACS $18 \mathrm{~h}$ later and compared to untreated AS160-transfected MCF7 cells (set at 100\%). Shown is the mean of triplicate experiments. d, S. typhimurium effector SopB activates AKT. AKT1 targets PAK4, which phosphorylates GEF-H1, thus controlling RHOA, RAC1 and actin. AKT1 also phosphorylates the RAB14-GAP, AS160. This prevents AS160 binding to phagosomal membranes, thus activating RAB14 and inhibiting phagosomal maturation. 
maturation $^{24}$. RabD, the $D$. discoideum RAB14, regulates phagocytosis and homotypic phagosome and lysosome fusion ${ }^{25}$. We followed GFP-RAB14 during infection with control or SopB-deficient DsRedS. typhimurium (Supplementary Fig. 16c). GFP-RAB14 localized on trans-Golgi and endosomal structures and was recruited to phagosomes only with SopB-expressing S. typhimurium. Because Rab GTPases cycle between active membrane-bound GTP and inactive cytosolic GDP forms, the Rab cycle can be monitored in living cells using photo-activation protocols (Supplementary Fig. 16d). The $t_{1 / 2}$ of phagosomal membrane dissociation of GTP-loaded PAGFPRAB14 was $70 \mathrm{~s}$, and this markedly decreased following inhibition of AKT in S. typhimurium-infected cells (Supplementary Fig. 16e).

The RAB14 cycle may be accelerated by AS160 (ref. 26) (the AKT substrate of $160 \mathrm{kDa}$; TBC1D4), a potential RAB14-GTPase activator protein (GAP). This may explain how AKT affects the RAB14 cycle. Silencing AS160 by shRNA constructs-but also in vitro GTP hydrolysis experiments-identified AS160 as the GAP for RAB14 (Supplementary Fig. 16f). AS160 becomes inactivated following phosphorylation by AKT and fails to bind membranes ${ }^{26}$. Chemically inhibiting AKT after activation by S. typhimurium accelerates the RAB14 cycle (Supplementary Fig. 16e), suggesting bacterial effectors like SopB activate AKT (at the plasma membrane; Fig. 5a) to phosphorylate cytosolic AS160. Phosphorylated AS160 then fails to bind to phagosomal membranes and RAB14 remains activated. Active RAB14 then recruits (unidentified) effectors that inhibit phagosomal fusion with lysosomes ${ }^{24}$. AKT1 inhibitors counteract these bacterial manipulations of the host machinery, resulting in bacterial growth inhibition. To test whether AKT activity on AS160 and RAB14 affects intracellular growth of bacteria, we introduced an shRNA for AS160 or an expression vector for AS160 or RAB14 in MCF7 cells before infection with DsRed-S. typhimurium. Cells were cultured following infection with inhibitor AKTil/ 2 for $18 \mathrm{~h}$ before FACS analyses to determine intracellular growth (Fig. 5c). Inhibition of AKT1 restricted intracellular growth of S. typhimurium, which was partially reversed by downregulating AS160 or overexpressing its target, RAB14. This suggests that AKT inhibitors control RAB14 via AS160, inducing phagosomal maturation to phagolysosomes, and thus controlling intracellular bacterial growth. How other kinases identified in the screen (Fig. 3b, c) contribute to bacterial survival remains to be determined.

Thus, AKT1 acts as a master regulator by controlling at least three GTPases and two essential host pathways, notably PAK4-RAC1/ RHOA and AS160-RAB14, which can be exploited by various intracellular pathogens for intracellular survival ${ }^{17,27}$ (Fig. 5d). Our AKT inhibitors counteract this bacterial manipulation of host processes, resulting in antibiotic activities.

We have used reciprocal chemical genetics to identify host kinases that are essential in controlling intracellular infections and can be targeted by novel chemical compounds to control infection in vitro and delay infection-induced mortality in vivo. This procedure reverses the normal route followed in drug discovery in which first a target and then a compound is defined. Our rationale was to identify a class of proteins (kinases) using chemical inhibitors with relevant biological activities. Subsequent synthesis of inhibitor variants for chemical profiling, and RNAi screening of the relevant protein family, identified potential host targets. AKT1 was identified by this approach and implicated in intracellular survival of S. typhimurium and other pathogens. We identified an inhibitor of AKT with limited specificity that still showed therapeutic potential as an antibiotic without noticeable side effects in mice, and we identified new mechanisms of bacterial manipulation of host cells. Other AKT inhibitors are already in phase II trials as anti-cancer drugs ${ }^{28}$ because AKT is found activated in many human tumours. Chronic infections are linked to increased cancer incidences. Patients with chronic Salmonella typhi infections, which usually reside in the biliary tract, have a reported tenfold higher incidence in gallbladder cancer ${ }^{29}$. Sustained activation of the AKT pathway by SopB for the survival of the intracellular S. typhi may well contribute towards cell transformation and gallbladder cancer. Many anti-cancer drugs were a spin-off from the search for antibiotics in the 1950s. Conversely, the current development of inhibitors of AKT, PAK4 and other kinases as anti-cancer drugs may yield novel antibiotics that counteract host pathways activated by intracellular pathogens for survival.

\section{METHODS SUMMARY}

Molecular methods, reagents and chemistry. The cloning of various constructs, generation of various S. typhimurium strains, growth and infection conditions, and in vitro kinase and GTPase assays are described in detail in the Methods. The details on the chemistry of the H-89 variants with nuclear mass resonance and mass spectrometry information are supplied in Supplementary Fig. 2. The details of the large-scale synthesis of ETB067 for the in vivo mouse experiments are given in Supplementary Fig. 2. The Student's $t$-test was applied where indicated. Confocal microscopy and live-cell imaging. Confocal microscopy was performed with a Leica AOBS LSCM (Leica Microsystems) equipped with a $405 \mathrm{~nm}$ laser for photo-activation experiments in a $37^{\circ} \mathrm{C}$ climate chamber. For details, see Methods. The decay of phagosomal photo-activatable-GFPRAB14 was calculated using MATLab software.

Automated microscopy, siRNA screening of the human kinome and statistical analysis. MCF7 cells were transfected with pooled siRNAs for every individual kinase (Dharmacon) present in the human genome before infection with GFP-S. typhimurium and analysis by automated microscopy (BD Pathway Bioimager). Images were analysed with CellProfiler (open-source cell image analysis software; Supplementary Figs 3, 5 and 6). The image statistics are shown in Methods. The heat map was generated using MATLAB software. Targets were validated with multiple individual siRNAs for the same target using Lux-S. typhimurium, and were quantified by luminometry. Pathway analysis was performed using Ingenuity Pathway Analysis programs. For details, see Methods.

Full Methods and any associated references are available in the online version of the paper at www.nature.com/nature.

\section{Received 4 July; accepted 4 October 2007.}

1. Walsh, $C$. Molecular mechanisms that confer antibacterial drug resistance. Nature 406, 775-781 (2000)

2. Meresse, S. et al. Controlling the maturation of pathogen-containing vacuoles: a matter of life and death. Nature Cell Biol. 1, E183-E188 (1999).

3. Vergne, I., Chua, J., Singh, S. B. \& Deretic, V. Cell biology of mycobacterium tuberculosis phagosome. Annu. Rev. Cell Dev. Biol. 20, 367-394 (2004).

4. Boucrot, E., Henry, T., Borg, J. P., Gorvel, J. P. \& Meresse, S. The intracellular fate of Salmonella depends on the recruitment of kinesin. Science 308, 1174-1178 (2005).

5. Harrison, R. E., Bucci, C., Vieira, O. V., Schroer, T. A. \& Grinstein, S. Phagosomes fuse with late endosomes and/or lysosomes by extension of membrane protrusions along microtubules: role of Rab7 and RILP. Mol. Cell. Biol. 23, 6494-6506 (2003)

6. Uchiya, K. \& Nikai, T. Salmonella enterica serovar Typhimurium infection induces cyclooxygenase 2 expression in macrophages: involvement of Salmonella pathogenicity island 2. Infect. Immun. 72, 6860-6869 (2004).

7. Kashina, A. S. et al. Protein kinase A, which regulates intracellular transport, forms complexes with molecular motors on organelles. Curr. Biol. 14, 1877-1881 (2004).

8. Engh, R. A., Girod, A., Kinzel, V., Huber, R. \& Bossemeyer, D. Crystal structures of catalytic subunit of cAMP-dependent protein kinase in complex with isoquinolinesulfonyl protein kinase inhibitors $\mathrm{H7}, \mathrm{H} 8$, and H89. Structural implications for selectivity. J. Biol. Chem. 271, 26157-26164 (1996).

9. Berns, K. et al. A large-scale RNAi screen in human cells identifies new components of the p53 pathway. Nature 428, 431-437 (2004).

10. Agaisse, $\mathrm{H}$. et al. Genome-wide RNAi screen for host factors required for intracellular bacterial infection. Science 309, 1248-1251 (2005).

11. Philips, J. A., Rubin, E. J. \& Perrimon, N. Drosophila RNAi screen reveals CD36 family member required for mycobacterial infection. Science 309, 1251-1253 (2005).

12. Pelkmans, L. et al. Genome-wide analysis of human kinases in clathrin- and caveolae/raft-mediated endocytosis. Nature 436, 78-86 (2005).

13. Davies, T. G. et al. A structural comparison of inhibitor binding to PKB, PKA and PKA-PKB chimera. J. Mol. Biol. 367, 882-894 (2007).

14. Chua, J., Vergne, I., Master, S. \& Deretic, V. A tale of two lipids: Mycobacterium tuberculosis phagosome maturation arrest. Curr. Opin. Microbiol. 7, 71-77 (2004).

15. Pendaries, C. et al. Ptdlns5P activates the host cell PI3-kinase/Akt pathway during Shigella flexneri infection. EMBO J. 25, 1024-1034 (2006)

16. Hernandez, L. D., Hueffer, K., Wenk, M. R. \& Galan, J. E. Salmonella modulates vesicular traffic by altering phosphoinositide metabolism. Science 304 1805-1807 (2004)

17. Knodler, L. A., Finlay, B. B. \& Steele-Mortimer, O. The Salmonella effector protein SopB protects epithelial cells from apoptosis by sustained activation of Akt. J. Biol. Chem. 280, 9058-9064 (2005). 
18. Scott, C. C. et al. Phosphatidylinositol-4,5-bisphosphate hydrolysis directs actin remodeling during phagocytosis. J. Cell Biol. 169, 139-149 (2005).

19. Wells, C. M., Abo, A. \& Ridley, A. J. PAK4 is activated via PI3K in HGF-stimulated epithelial cells. J. Cell Sci. 115, 3947-3956 (2002).

20. Callow, M. G., Zozulya, S., Gishizky, M. L., Jallal, B. \& Smeal, T. PAK4 mediates morphological changes through the regulation of GEF-H1. J. Cell Sci. 118, 1861-1872 (2005)

21. Qu, J. et al. Activated PAK4 regulates cell adhesion and anchorage-independent growth. Mol. Cell. Biol. 21, 3523-3533 (2001).

22. Rupper, A. C., Rodriguez-Paris, J. M., Grove, B. D. \& Cardelli, J. A. p110-related $\mathrm{PI}$ 3-kinases regulate phagosome-phagosome fusion and phagosomal $\mathrm{pH}$ through a PKB/Akt dependent pathway in Dictyostelium. J. Cell Sci. 114, 1283-1295 (2001).

23. Smith, A. C. et al. A network of Rab GTPases controls phagosome maturation and is modulated by Salmonella enterica serovar Typhimurium. J. Cell Biol. 176, 263-268 (2007).

24. Kyei, G. B. et al. Rab14 is critical for maintenance of Mycobacterium tuberculosis phagosome maturation arrest. EMBO J. 25, 5250-5259 (2006).

25. Harris, E. \& Cardelli, J. RabD, a Dictyostelium Rab14-related GTPase, regulates phagocytosis and homotypic phagosome and lysosome fusion. J. Cell Sci. 115, 3703-3713 (2002)

26. Miinea, C. P. et al. AS160, the Akt substrate regulating GLUT4 translocation, has a functional Rab GTPase-activating protein domain. Biochem. J. 391, 87-93 (2005).

27. Pizarro-Cerda, J. \& Cossart, P. Subversion of phosphoinositide metabolism by intracellular bacterial pathogens. Nature Cell Biol. 6, 1026-1033 (2004).

28. Granville, C. A., Memmott, R. M., Gills, J. J. \& Dennis, P. A. Handicapping the race to develop inhibitors of the phosphoinositide 3-kinase/Akt/mammalian target of rapamycin pathway. Clin. Cancer Res. 12, 679-689 (2006).
29. Strom, B. L. et al. Risk factors for gallbladder cancer. An international collaborative case-control study. Cancer 76, 1747-1756 (1995).

Supplementary Information is linked to the online version of the paper at www.nature.com/nature.

Acknowledgements This work was supported by a program grant from N.W.O. and the Dutch Cancer Society KWF to J.N. and T.H.M.O., and an EEC network grant (Microban). We thank J. Sung for the histochemical analyses of mouse tissues, W. Mooi and W. Zwart for kinase-compound modelling, S. Commandeur and K. Walburg for support in the chemical-profiling experiments, D. Holden for SopB-deficient S. typhimurium, L. Wilson for help with culturing M. tuberculosis strains, H. v. d. Elst for assistance in purification and LCMS analysis of the chemical inhibitors, K. Kremer for providing M. tuberculosis clinical isolates, K. Nealson and S. Vesterlund for Lux-S. typhimurium, C. Wells and A. Ridley for haemagglutinin-tagged PAK4 contructs, and G. Lienhard for AS160 constructs.

Author Contributions C.K. performed the kinase assays (with J.N.) and experiments with RAB14, AS160 (with M.K.) and PAK4. M.M. and C.K. performed the shRNAi screen with a library made by R.L.B. and obtained from D.A.E. C.K. performed the siRNA screening, automated microscopy and data analyses, supported by the NKI robotics facility (R.L.B., D.E.). Subcloning and sequencing was by L.J. A.T., R.v.d.N. and A.P. synthesized the kinase inhibitors under the supervision of H.O. and G.v.d.M. N.D.L.S., S.J.F.v.d.E. and A.G. performed in vivo and chemical-profiling experiments (supervised by T.H.M.O.). J.N. supervised the study.

Author Information Reprints and permissions information is available at www.nature.com/reprints. Correspondence and requests for materials should be addressed to J.N. (j.neefjes@nki.nl). 


\section{METHODS}

Constructs and reagents. For the in vitro kinase assay the following Image clones encoding kinases were ordered at the MGC or ORIGENE and their kinase domains cloned by PCR into the pEGFP-C1 mammalian expression vector (Clontech): full-length $A K T 1$ (T308D, S473D) and the DNA encoding the catalytically active forms were a gift of M. Voorhoeve. Full-length PAK4 (amino acids 2-591, Origene, NM_005884.3), PRKD2 (438-721, MGC4127433), fulllength PCTK1 (5153A) and CAMK2B (10-573, MGC29528) were used as templates for generating GFP-tagged kinase domains using specific PCR primers. HA-PAK4 constructs were a gift of C. Wells and A.Ridley ${ }^{30}$. HA-tagged AS160 constructs ${ }^{31}$ were a gift of G. Lienhard. The CD8 expression construct is described in ref. 32. The construct encoding CaPAK4 $(\mathrm{S} 445 \mathrm{~N})^{33}$ was made by PCR.

For GFP-RAB14, full-length human RAB14 complementary DNA (IMAGE: 2963119) was amplified by PCR. The PCR fragment was cloned into pGEMTeasy (Promega), and then pEGFP C1 (Clontech), to obtain constructs encoding amino-terminal enhanced-GFP-tagged RAB14. EGFP was exchanged for photo-activatable-GFP ${ }^{34}$ using the PA-GFP construct.

RNAi against $A S 160$ was performed according to a procedure described previously $y^{35}$. In short, a primer directing the synthesis of shRNA complementary to human AS160, was cloned $5^{\prime}$ of the H1-RNA promoter in the PSUPER vector. The target sequence shRNAi AS160.1 corresponds to AS160394-416 nucleotides (sequence: 5'-AACAGCCACGACCTCACCTACTT), and shRNAi AS160.2 to an already characterized sequence ${ }^{36}$. The specificity of the target sequences was verified by BLAST search against the gene data bank.

PKI was a gift from J. Zhang ${ }^{37}$ and subcloned into pIRES2-DsRed2 (Clontech). All DNA constructs were verified by sequencing.

Antibodies. Antibodies used were: rabbit polyclonal anti-CD63 (ref. 38) and mouse monoclonal anti-human-CD63 (Cymbus Biotechnology), mouse monoclonal anti-human-CD8 (BD Biosciences), mouse monoclonal anti-humanAKT(2H10) and rabbit monoclonal phospho-AKT(193H12) (Cell Signalling), and mouse monoclonal anti-human LC3 (nanoTOOLS). In addition: rabbit polyclonal anti-S. typhimurium-LPS (Difco laboratories) and mouse monoclonal 1E6 anti-S. typhimurium-LPS (Biodesign International). Secondary antibodies were: Alexa 488- or Texas Red/Alexa 568-conjugated mouse or rabbit (Molecular Probes).

Cell lines. MCF7 cells were maintained in Iscoves medium (GIBCO-BRL) supplemented with $7.5 \% \mathrm{FCS}, 2 \mathrm{mM}$ glutamine, $100 \mathrm{U} \mathrm{ml}^{-1}$ penicillin, $100 \mu \mathrm{g} \mathrm{ml}^{-1}$ streptomycin at $37^{\circ} \mathrm{C}$ in $5 \% \mathrm{CO}_{2}$. Human primary macrophages (mfl) were generated by differentiating human monocytes ${ }^{39}$.

Animals. Female 6-8-week-old BALB/c, C57BL/6 and C3H/HeNHsd mice were purchased from Charles River Laboratories and maintained in specific pathogen-free conditions within the animal facility at the LUMC. All experiments were ethically approved (Leiden LUMC UDEC 05103).

Inhibitors. All inhibitors were used at concentrations reported to inhibit their kinase target. The PKA inhibitor H-89 (Biomol or Sigma) was used at a concentration of $10 \mu \mathrm{M}$, Rp-cAMP (Biomol) was used at a concentration of $100 \mu \mathrm{M}$. The following RHO kinase inhibiters were used: H-1152 and Y-27632 (Calbiochem) at concentrations of 10 and $50 \mu \mathrm{M}$. SB203580 (Invitrogen) was used to inhibit p38MAPK, and LY 294002 (Calbiochem) was used to inhibit PI3K (concentrations 10 and $50 \mu \mathrm{M}$ ). Casein kinase was inhibited by DRB (5,6Dichloro-1- $\beta$-D-ribofuranosylbenzimidazole, Calbiochem) and calmodulin kinase by KN-93 (Calbiochem) at concentrations of 10 and $50 \mu \mathrm{M}$. Myosin light-chain kinase was inhibited by ML-7 (Biomol) at $20 \mu \mathrm{M}$ concentration. The PKB inhibitor AKTil/2 (Calbiochem) was used at a concentration of $10 \mu \mathrm{M}$. Inhibitors were added $1 \mathrm{~h}$ post infection along with $\left(10 \mu \mathrm{g} \mathrm{ml}^{-1}\right)$ gentamycin to eliminate extracellularly growing $S$. typhimurium to determine the effects on intracellular growth of $S$. typhimurium.

Construction of new chemical compounds based on $\mathrm{H}-89$ is described in detail in Supplementary Fig. 2. These compounds were dissolved in 100\% ethanol.

Bacterial strains, growth conditions and infections. The Salmonella strains S. typhimurium SL1344 and GFP-S. typhimurium SL1344 ${ }^{40}$ were a gift from S. Meresse. Control and SopB-deficient S. typhimurium 12023 were a gift from D. Holden. DsRED (pMW266, a gift from D. Bumann) was expressed in S. typhimurium SL1344 (ref. 41). This construct was isolated and expressed in the various S. typhimurium 12023 strains. The lux operon from P. luminescence (luxCD-ABE) was isolated from S. typhimurium 14028 (a gift of S. Vesterlund) ${ }^{42}$ and expressed in S.typhimurium 12023. MCF-7 cells were cultured at $37^{\circ} \mathrm{C}$ in $5 \%$ $\mathrm{CO}_{2}$ for $48 \mathrm{~h}$ in Iscoves medium without antibiotics. After overnight growth at $37^{\circ} \mathrm{C}$ with shaking, bacteria were subcultured at a dilution of 1:33 in fresh LB medium and incubated for $3.5 \mathrm{~h}$ at $37^{\circ} \mathrm{C}$ with shaking. MCF- 7 cells were infected at multiplicity of infection (m.o.i.) 100 (100 bacteria per cell unless indicated otherwise) in Iscoves without antibiotics for $30 \mathrm{~min}$ at $37^{\circ} \mathrm{C}$ in $5 \% \mathrm{CO}_{2}$. Infected cells were washed 4-6 times and incubated for $1 \mathrm{~h}$ in tissue culture medium containing $100 \mu \mathrm{g} \mathrm{ml}^{-1}$ gentamycin (GIBCO) to eliminate extracellular bacteria. Infected cells were subsequently incubated for the indicated time points in medium containing $10 \mu \mathrm{g} \mathrm{ml}^{-1}$ gentamycin.

Primary macrophages were infected in quadruplicate wells with log phase cultures of S. typhimurium or mycobacteria (M. smegmatis, H37Rv M. tuberculosis or MDR-M. tuberculosis (Beijing/W family resistant to rifampacin, isoniazide, ethambutol and pyrazinamide ${ }^{43}$ ) at an m.o.i. of 5 for $1 \mathrm{~h}$ at $37^{\circ} \mathrm{C}$. Inoculum was verified by c.f.u. assays on $7 \mathrm{H} 10$ plates. Extracellular bacteria were physically removed and the medium replaced with gentamycin-containing medium $\left(3 \mu \mathrm{g} \mathrm{ml}^{-1}\right)$ and $10 \mu \mathrm{M}$ of the appropriate kinase inhibitor. For experiments lasting more than $24 \mathrm{~h}$, medium containing gentamycin and $10 \mu \mathrm{M}$ kinase inhibitor was refreshed daily. To recover the bacteria from the infected macrophages, macrophages were washed 3 times with PBS before lysis in $\mathrm{H}_{2} \mathrm{O}$, and serial dilutions of lysates were plated out on $7 \mathrm{H} 10$ plates. Colony-forming units were counted after 2 days for M. smegmatis, 1 day for S. typhimurium, and after 3 weeks for M. tuberculosis. Lux activity could be directly (in the absence of exogenous substrates) detected through the activity of proteins encoded in the $P$. luminescence (lux $C D-A B E$ ) operon. The lux $C D E$ gene products are required for the synthesis of long-chain fatty aldehydes that were used as substrate for light production by the luxAB gene products ${ }^{42}$. Light was detected by chemoluminescence (Lumat LB 9507 EG\&G BERTHOLD). Alternatively, internalization and expansion of GFP-S. typhimurium was determined by two-colour FACS, in which CD8 was detected as a transfection marker. Two-colour FACS was also used when the effect of GFP-tagged proteins on expansion of DsRED-S. typhimurium was determined.

In vivo experiments to determine the activity of ЕTВ067 on S. typhimurium survival. S. typhimurium (SL1344) were grown statically and $2 \times 10^{3}$ cells (in a volume of $100 \mu \mathrm{l}$ of PBS) were injected intraperitoneally in female 8-12-week-old $\mathrm{C} 3 \mathrm{H} / \mathrm{HeNH}$ sd mice. Mice were given a single dose of $4 \mathrm{mg}$ ETB067 in 8\% ethanol/PBS solution (vehicle control, $8 \%$ ethanol only), intraperitoneally, in a volume of $100 \mu$ per injection at day 6 and 8 post infection, when the animal showed visible signs of infection on the basis of weight loss. Mice were maintained in SPF conditions and the experiments were approved by the local ethical committee of the LUMC, Leiden (DEC protocol 05103).

siRNA screen of the human kinome, validation and qPCR. A synthetic siRNA library was obtained from Dharmacon, targeting 779 kinases and kinaserelated proteins (Human siARRAY SMARTpool Reagent - Protein Kinases; Dharmacon). MCF-7 cells were seeded in 384 well $\mu$ CLEAR plates (Greiner bio-one) at 2,000 cells per well. Reversed transfection was done with $0.1 \mu \mathrm{l}$ Dharmafect 4 and $50 \mathrm{nM}$ siRNA in a total volume of $50 \mu \mathrm{l}$. Transfection efficiency (tested with siRNA for GAPDH) exceeded 95\% under these conditions. The transfected cells were cultured for $48 \mathrm{~h}$ and infected with GFP-S. typhimurium SL1344 ( $50 \mu \mathrm{l}$ of $2.67 \times 10^{7}$ bacteria per $\mathrm{ml}$ ), according to the protocol described above. Eighteen hours post infection, the cells were fixed with 3.75\% formaldehyde in PBS for $1 \mathrm{~h}$. The nuclei were stained with Hoechst $33342\left(2 \mu \mathrm{g} \mathrm{ml}^{-1}\right)$ (Molecular Probes), and the cell membranes with Wheat Germ Agglutinin (WGA) Alexa Fluor 647 (Molecular Probes). The microplates were imaged with the BD Pathway Bioimager (Becton Dickinson) with the following filters: Hoechst 33342 excitation 380/10, epifluorescence 400 DCLP, emission 435 LP; GFP excitation 470/10, epifluorescence Fura/FITC, emission 515 LP; WGA Alexa 647 excitation 635/20, epifluorescence 84,000, emission 84,101. The images were analysed with open-source cell image analysis software (www.cellprofiler.org) ${ }^{44}$. First, nuclei were identified, based on the Hoechst 33342 stain. Cell boundaries were then identified using the nuclear stain as a reference point and determining the WGA Alexa Fluor 647 fluorescence. From the data, the rate of intracellular proliferation of GFP-S. typhimurium was calculated, as depicted in Supplementary Fig. 3.

Data analysis, programming and statistical analyses are discussed in Supplementary Figs 5 and 6, and below.

Using MATLAB, the results were plotted as heat maps containing the individual kinases and kinase-related siRNAs. SiRNAs reducing intracellular growth of S. typhimurium were visually inspected to exclude any image artefacts. The siRNA screen of the human kinome was performed twice in triplicate with four images made of every individual well (36 images in total).

The mean GFP fluorescence per cell was measured and plotted as a histogram per image. For intracellular growth of S. typhimurium, H-89-treated samples were taken as a reference. Median (triplicate) GFP fluorescence per infected cells was compared between siRNA transfected and H-89-treated MCF7 cells and plotted in a heat map or as a bar diagram.

To validate the hits further, multiple individual siRNA sequences per target (Dharmacon) were tested for their effect on intracellular growth of Lux-S. typhimurium. Effects on intracellular growth were determined by luminometry. A hit was considered validated when confirmed by at least two independent siRNAs. The siRNA sequences validating the hits were: Supplementary Fig. 8a. The effects 
of the different siRNAs on messenger RNA expression were determined by qPCR. For primer (Sigma) sequences used, see Supplementary Fig. 8a.

Role of PKB/AKT and downstream effectors in control intracellular S. typhimurium growth. MCF7 cells were transfected with expression constructs for PAK4, PAK4(S445N), GFP-RAB14 or the shRNA for AS160 and infected 48hr later with lux-S. typhimurium. $1 \mathrm{~h}$ post-infection, cells were cultured further in the presence or absence of the PKB/Akt inhibitor AKTil/2 for $18 \mathrm{~h}$ before intracellular growth of lux-S. typhimurium was measured by luminometry.

In vitro kinase activity assays. GFP-tagged full-length kinases or kinase domains were expressed in HEK293 cells by DEAE-dextran transfection. Proteins were isolated using anti-GFP pre-coupled IgG Dynabeads (Invitrogen). AKT (Upstate) contained additional kinase activities and we used immunopurified AKT1 instead. PKA (Sigma) was used in in vitro kinase assays. Kinase assays were performed in triplicate in a $40 \mu \mathrm{l}$ volume containing: $20 \mathrm{mM}$ MOPS; $25 \mathrm{mM}$ $\beta$-glycerol phosphate, $\mathrm{pH} 7.2 ; 1 \mathrm{mM}$ EGTA; $1 \mathrm{mM}$ sodium orthovanadate; $1 \mathrm{mM}$ dithiothreitol; $20 \mu \mathrm{M}$ non-radioactive ATP; $15 \mathrm{mM} \mathrm{MgCl}_{2} ; 10 \mu \mathrm{g}$ Myelin Basic Protein (MBP; Sigma); $0.5 \mu \mathrm{l}\left[\gamma_{-}{ }^{32} \mathrm{P}\right]$ ATP $\left(2 \mathrm{mCi} \mathrm{ml}^{-1}\right.$; GE Healthcare); chemical inhibitors (dissolved in DMSO) or vehicle control (DMSO). To detect AKT1 activity, a Crosstide synthetic peptide with two additional carboxyterminal lysine residues (GRPRTSSFAEGKK) was used. This peptide is suitable as a substrate for kinases, including AKT, SGK, p70S6 kinase and MST1. The double lysine modification enables binding to P81 paper in radioactive kinase assays. The reactions were started by addition of the isolated beads with GFPkinase domains or isolated proteins. In all reactions, DMSO constitutes $8 \%$ of the volume. Inhibitors were tested at $0,1.25,2.5,5,10,20,40$ and $80 \mu \mathrm{M}$ final concentrations and from the inhibition curves the $\mathrm{IC}_{50}$ values were determined. In vitro kinase reactions were incubated at $37^{\circ} \mathrm{C}$ for $20-120 \mathrm{~min}$ (depending on the kinase) and terminated by spotting $20 \mu$ of the reaction volume on P81 paper (Whatman). Free $\left[\gamma-{ }^{32} \mathrm{P}\right]$ ATP was removed by extensive washing in $0.65(\mathrm{v} / \mathrm{v}) \%$ phosphoric acid, followed by one acetone wash and air-drying. Phosphorylation of MBP was detected using phosphorimager plates read by phosphoimaging (Fujix BAS 2000) and quantified by AIDA software.

In vitro GTPase assay. The GTPase assay was performed as described previously ${ }^{45}$. Briefly, GST-RAB14 (amino acids 1-212) was produced in Escherichia coli, purified and loaded with $\left[\gamma^{-}{ }^{32} \mathrm{P}\right]$ GTP $\left(10 \mathrm{mCiml}^{-1},>\right.$ $5,000 \mathrm{Cimmol}^{-1}$; GE Healthcare) in the presence of $10 \mathrm{mM}$ EDTA. Subsequently, $\mathrm{MgCl}_{2}$ was added to a final concentration of $20 \mathrm{mM}$, followed by gel filtration on a Bio-Spin 6 column (BioRad) equilibrated with buffer $(0.1 \mathrm{M}$ Tris- $\mathrm{HCl}, \mathrm{pH} 7.5,10 \mathrm{mM} \mathrm{MgCl}_{2}, 2 \mathrm{mM}$ dithiothreitol, $0.5 \mathrm{M} \mathrm{NaCl}$ ) to remove free $\left[\gamma_{-}{ }^{32} \mathrm{P}\right]$ GTP. Reaction mixtures containing the different fusion proteins in reaction buffer ( $40 \mathrm{mM}$ Tris- $\mathrm{HCl}, \mathrm{pH} 8.0,50 \mathrm{mM} \mathrm{NaCl}, 8 \mathrm{mM} \mathrm{MgCl}, 1 \mathrm{mM}$ dithiothreitol, $0.5 \mathrm{mM}$ non-radioactive GTP, $0.1 \mathrm{mg} \mathrm{ml}^{-1}$ BSA, $1 \mathrm{mM}$ phosphate, $1 \%$ glycerol) were assembled on ice. To investigate the GAP activity of AS160 towards RAB14, GST-RAB14 was incubated with different concentrations of GST-AS160 (GAP-domain, amino acids 856-1182). Individual reactions were stopped by adding $1 \mathrm{ml}$ of charcoal suspension ( $7 \% \mathrm{w} / \mathrm{v}$ charcoal, $10 \%$ $\mathrm{v} / \mathrm{v}$ ethanol, $\left.0.1 \mathrm{M} \mathrm{HCl}, 10 \mathrm{mM} \mathrm{KH}_{2} \mathrm{PO}_{4}\right)^{46}$, and the mixture was centrifuged for $5 \mathrm{~min}$ in an Eppendorf centrifuge. Release of $\left[{ }^{32} \mathrm{P}\right]$-orthophosphate was quantified by liquid-scintillation-counting of the supernatant.

Cells were fixed and immuno-stained before analysis by confocal laser-scanning microscopy. Fixation was either in $3.7 \%$ formaldehyde for $15 \mathrm{~min}$ at room temperature followed by permeabilization in $0.1 \%$ Triton-X100 or in methanol $\left(-20^{\circ} \mathrm{C}\right)$ for $2 \mathrm{~min}$.

Confocal analyses were performed using a Leica TCS SP or AOBS confocal laser-scanning microscope (CLSM; Leica Microsystems). Green fluorescence was detected at $\lambda>515 \mathrm{~nm}$ after excitation at $\lambda=488 \mathrm{~nm}$. For dual analyses, green fluorescence was detected at $\lambda=520-560 \mathrm{~nm}$. Red fluorochromes were excited at $\lambda=568 \mathrm{~nm}$ and were detected at $\lambda>585 \mathrm{~nm}$.

To detect active phosphorylated AKT or GFP-RAB7 in S. typhimuriuminfected MCF7 cells, these cells were infected with SopB- or control S. typhimurium 12023 for $45 \mathrm{~min}$ before fixation. Activated AKT was stained with anti-phosphoAKT (Cell Signalling) and secondary ALEXA-488-coupled antibodies before image analyses by CLSM.

For uptake experiments, GFP-RAB14-expressing MCF7 cells were infected with DsRED-labelled control or SopB-deficient S. typhimurium 12023 for $45 \mathrm{~min}$ before analyses by CLSM.

For photo-activation experiments, PA-GFP-RAB14-transfected MCF7 cells were infected with DsRED-labelled control or SopB-deficient S. typhimurium 12023 for $45 \mathrm{~min}$, and living cells analysed in a $37^{\circ} \mathrm{C}$ culture hood on a Leica AOBS CLSM (Leica Microsystems). The PA-GFP-RAB14 cycle was determined by photoactivation analysis ${ }^{47}, 48$, in which the loss of membrane-associated PA-GFP-RAB14 was monitored after photo-activation with a $405 \mathrm{~nm}$ laser light using a point-bleach mode, operational with Leica Software. The decay curves for loss of membrane-associated fluorescence were determined using MATLab software. Alternatively, the PA-GFP-RAB14 cycle, reflected by loss of membrane-bound fluorescence was determined in MCF7 cells expressing PA-GFPRAB14 in the presence or absence of the pSUPER shRNA constructs for AS160. Statistical analysis of the data generated with Cellprofiler. Two independent siRNA Screens were performed to identify kinases involved in intracellular replication of S. typhimurium. Data acquisition is described in Supplementary Figs 5 and 6.

Interpretation of the data requires computational and statistical analysis techniques. We generated a scored phenotype (reduced intracellular S. typhimurium growth only considering infected cells) list from the raw data with the opensource Bioconductor/R package and cellHTS ${ }^{49}$ (http://www.dkfz.de/signaling/ cellHTS). The results are formatted in a HTML format that enables viewing of all the results (http://nature.labstore.nl). Owing to the edge effect the data from the first screen could not be B-score ${ }^{50}$-normalized and therefore not ranked (although ranking is included). Only by considering a sample's direct neighbours, was determination of whether a particular siRNA reduced intracellular growth possible. In the second screen, the data could be B-score-normalized and ranked. Data from the first and second screen were both visually inspected to exclude any artefacts in the automated image analysis or artefacts that could not be resolved by the computational analyses. The heat map in Supplementary Fig. $8 \mathrm{c}$ is based on the results of computational analysis only. The hit table in Fig. $3 \mathrm{~b}$ is based on ranking, visual inspection and independent validation.

For statistics on the individual kinases see http://nature.labstore.nl.

30. Wells, C. M., Abo, A. \& Ridley, A. J. PAK4 is activated via PI3K in HGF-stimulated epithelial cells. J. Cell Sci. 115, 3947-3956 (2002).

31. Sano, H. et al. Insulin-stimulated phosphorylation of a Rab GTPase-activating protein regulates GLUT4 translocation. J. Biol. Chem. 278, 14599-14602 (2003).

32. Nilsson, T., Jackson, M. \& Peterson, P. A. Short cytoplasmic sequences serve as retention signals for transmembrane proteins in the endoplasmic reticulum. Cell 58, 707-718 (1989).

33. Qu, J. et al. Activated PAK4 regulates cell adhesion and anchorage-independent growth. Mol. Cell. Biol. 21, 3523-3533 (2001).

34. Patterson, G. H. \& Lippincott-Schwartz, J. Selective photolabeling of proteins using photoactivatable GFP. Methods 32, 445-450 (2004).

35. Brummelkamp, T. R., Bernards, R. \& Agami, R. A system for stable expression of short interfering RNAs in mammalian cells. Science 296, 550-553 (2002).

36. Larance, M. et al. Characterization of the role of the Rab GTPase-activating protein AS160 in insulin-regulated GLUT4 trafficking. J. Biol. Chem. 280, 37803-37813 (2005).

37. Zhang, J., Hupfeld, C. J., Taylor, S. S., Olefsky, J. M. \& Tsien, R. Y. Insulin disrupts $\beta$-adrenergic signalling to protein kinase $A$ in adipocytes. Nature $437,569-573$ (2005).

38. Vennegoor, C. et al. Biochemical characterization and cellular localization of a formalin-resistant melanoma-associated antigen reacting with monoclonal antibody NKI/C-3. Int. J. Cancer 35, 287-295 (1985).

39. Verreck, F. A. et al. Human IL-23-producing type 1 macrophages promote but IL10-producing type 2 macrophages subvert immunity to (myco)bacteria. Proc. Natl Acad. Sci. USA 101, 4560-4565 (2004).

40. Meresse, S., Steele-Mortimer, O., Finlay, B. B. \& Gorvel, J. P. The rab7 GTPase controls the maturation of Salmonella typhimurium-containing vacuoles in HeLa cells. EMBO J. 18, 4394-4403 (1999).

41. Zwart, W. et al. Spatial separation of HLA-DM/HLA-DR interactions within MIIC and phagosome-induced immune escape. Immunity 22, 221-233 (2005).

42. Vesterlund, S., Paltta, J., Laukova, A., Karp, M. \& Ouwehand, A. C. Rapid screening method for the detection of antimicrobial substances. J. Microbiol. Methods 57, 23-31 (2004).

43. Kremer, K. et al. Comparison of methods based on different molecular epidemiological markers for typing of Mycobacterium tuberculosis complex strains: interlaboratory study of discriminatory power and reproducibility. J. Clin. Microbiol. 37, 2607-2618 (1999).

44. Carpenter, A. E. et al. CellProfiler: image analysis software for identifying and quantifying cell phenotypes. Genome Biol. 7, R100 (2006).

45. Askjaer, P. et al. RanGTP-regulated interactions of CRM1 with nucleoporins and a shuttling DEAD-box helicase. Mol. Cell. Biol. 19, 6276-6285 (1999).

46. Bischoff, F. R. \& Ponstingl, H. Catalysis of guanine nucleotide exchange of Ran by RCC1 and stimulation of hydrolysis of Ran-bound GTP by Ran-GAP1. Methods Enzymol. 257, 135-144 (1995).

47. Dantuma, N. P., Groothuis, T. A., Salomons, F. A. \& Neefjes, J. A dynamic ubiquitin equilibrium couples proteasomal activity to chromatin remodeling. J. Cell Biol. 173, 19-26 (2006).

48. Jordens, I. et al. The Rab7 effector protein RILP controls lysosomal transport by inducing the recruitment of dynein-dynactin motors. Curr. Biol. 11, 1680-1685 (2001).

49. Boutros, M., Bras, L. P. \& Huber, W. Analysis of cell-based RNAi screens. Genome Biol. 7, R66 (2006)

50. Malo, N., Hanley, J. A., Cerquozzi, S., Pelletier, J. \& Nadon, R. Statistical practice in high-throughput screening data analysis. Nature Biotechnol. 24, 167-175 (2006). 